\title{
Readiness for Hospital Discharge of Adult Patients with Major Depressive Disorder in China: A Cross-Sectional Study
}

\author{
Lile Xiong (1D' \\ Yingying Liu $^{2}$ \\ Qiongni Chen ${ }^{3}$ \\ Yusheng Tian ${ }^{3}$ \\ Min Yang'
}

'Xiangya Nursing School of Central South University, Changsha, Hunan Province, People's Republic of China; ${ }^{2}$ West China Hospital Sichuan University, Chengdu, Sichuan Province, People's Republic of China; ${ }^{3}$ The Second Xiangya Hospital of Central South University, Changsha, Hunan Province, People's Republic of China
Correspondence: Min Yang Xiangya Nursing School of Central South University, 172 Tongzipo Road, Changsha City, Hunan Province, People's Republic of China

$\mathrm{Tel} / \mathrm{Fax}+8673182650275$

Email yangminzhu@csu.edu.cn
Purpose: Being ready for discharge is vital to successful hospital-to-home transitions. However, despite a wealth of evidence on its effectiveness, little is known about readiness for hospital discharge (RHD) in adult patients with major depressive disorder (MDD) and its influencing factors. In this study, we investigated the patient-reported RHD and its influencing factors among Chinese adult patients with MDD.

Patients and Methods: In this cross-sectional design study, 230 adult patients with MDD were recruited according to the inclusion and exclusion criteria, 6 were excluded due to incomplete questionnaires, finally 224 patients were included in our study. Data were collected from March to September 2019 in a tertiary general hospital in Hunan Province (China). The general information, RHD, quality of discharge teaching and level of depression were assessed by using questionnaires. Univariate analysis and ordinal logistic regression analysis were performed to explore the influencing factors of RHD.

Results: The RHD score was $7.37 \pm 1.40$, and $36.2 \%$ of participants were not ready for discharge. The score of quality of discharge teaching scale (QDTS) was $6.36 \pm 1.89$, the dimension of delivery scored highest, followed by content-needed and content-received. The proportions of patients with no, mild, moderate, moderately severe and severe depression were $12.5 \%, 27.7 \%, 25.0 \%, 25.4 \%$ and $9.4 \%$, respectively. The following factors were associated with RHD: the level of depression $(\mathrm{OR}=0.66)$, the content-received dimension of QDTS $(\mathrm{OR}=1.16)$, education level $(\mathrm{OR}=1.24)$, work status $(\mathrm{OR}=1.76)$ and length of hospitalization $(\mathrm{OR}=0.53)$.

Conclusion: The RHD among participants was at a moderate level. It is strongly suggested to take the assessment of RHD as a routine process. High education level, employment and the content-received dimension of QDTS were protective factors of participants' RHD, and long-term hospitalization, the high level of depression were its risk factors.

Keywords: depressive, discharge readiness, discharge education, inpatients

\section{Introduction}

Major depressive disorder (MDD) is a serious medical condition affecting public health. The number of patients with MDD is huge and many of them need to be hospitalized for treatment. According to data from the World Health Organization, there are about 350 million people suffering from MDD worldwide. ${ }^{1}$ In China, the lifetime prevalence of MDD is $3.4 \%{ }^{2}$ if China's population of 1.4 billion is considered, this prevalence value indicates that a very large number of individuals are affected by MDD. In most cases, lifetime MDD is considered moderate or 
severe, and the majority (about 70\%) of patients with lifetime MDD will receive treatments including medication and psychotherapy. At some point during their life, about $12 \%$ of patients with MDD are hospitalized overnight or longer. ${ }^{3}$ However, due to increasing economic pressure on health systems, reducing the length of hospitalization has become a default rule adopted to control costs and deal with the fiscal pressures of inpatient mental health services. ${ }^{4}$ Accordingly, the time allotted for patients' preparation for discharge has been shortened. ${ }^{5}$ As a result, most patients with MDD are discharged with residual symptoms. The residual symptoms may lead to negative outcomes. It is common to see psychiatric patients experience adverse events such as the exacerbation of symptoms immediately after discharge. ${ }^{6}$ It has been reported that $5.2-5.4 \%$ of patients with MDD had at least one readmission within 30 days of discharge. ${ }^{3}$ A study conducted in China also found patients with MDD still suffer from impairments in psychosocial and somatic domains of function despite being clinically qualified as cured. $^{7}$

Adverse events might be preventable or ameliorable by effective discharge planning, and readiness for hospital discharge (RHD) is a barometer of discharge planning. The results of Forster's study showed that $6-12 \%$ of adverse events were considered preventable. ${ }^{8}$ Previous work has highlighted that effective discharge planning protocols led to continuity of care and fewer hospital readmissions. ${ }^{9}$ Discharge planning is an ongoing, individualized program of care and support which meets the needs of patients on continuity of care. The components of discharge planning may vary in different countries due to differences in healthcare systems, but they can be generally summarized in four aspects: (1) patient assessment; (2) development of a discharge plan; (3) provision of service, including patient/family education and service referral; and (4) follow-up/evaluation. ${ }^{10}$ RHD can reflect the effects of discharge planning directly and immediately. Assessment of RHD of patients is also the last chance to adjust discharge planning before discharge.

Readiness for hospital discharge is a term used to describe a patient's ability to continue the recovery process after hospital discharge. It is also an indicator for whether patients can be discharged safely. ${ }^{11,12}$ Being ready for discharge has become increasingly important for patients' safe transition from hospital to home as well as for patients' satisfaction and positive outcomes. ${ }^{12,14}$ However, only $47.8 \%$ of inpatients felt prepared for discharge in a large-sample study. ${ }^{15}$ Patients who are unready for discharge might fail to deal with difficulties at home, which leads to a high risk of adverse events, such as reoccurrence or aggravation of disease, unplanned readmission, poor drug adherence, and so on. ${ }^{16-19}$ So, it is crucial to address the issue of RHD for patients.

The body of literature on RHD and its influencing factors has been growing in recent decades. Previous studies found that a considerable proportion of patients among various populations were unready for discharge, ${ }^{12,20-23}$ and the influence factors of RHD included age, marital status, length of hospitalization, depression, quality of discharge teaching, etc. ${ }^{22,24}$ However, evidence mainly focused on patients with somatic diseases. For patients with mental health disorders, studies of RHD abroad were conducted among patients with schizophrenia and anorexia nervosa. ${ }^{25,26}$ No studies were found to directly address RHD of depressive patients abroad. Two studies have been found to discuss RHD of patients with depression in China. ${ }^{24,27}$ Huang et al found RHD of patients with depression was at a moderate level, ${ }^{27}$ but they did not determine the influencing factors of RHD. The influencing factors from studies among patients with somatic diseases may not necessarily apply to patients with mental diseases. For example, quality of discharge teaching: patients with depression have been reported to have a diminished capacity for learning, which may affect their reported quality of discharge teaching. ${ }^{28}$ So, the influencing factors of RHD for patients with MDD need further study. Wang et al investigated the status quo of RHD and its influencing factors among 367 patients with depression. ${ }^{24}$ However, the age of the study population in Wang's study ranged from 12 to 87 years old and they reported age on average rather than age groups. Clinical discharge guidance for adolescent patients with depression is mainly provided to their caregivers, and in most cases, their discharge decisions are made by their caregivers and doctors. To develop discharge planning more precisely, it is necessary to describe RHD for patients in different age groups. Furthermore, the degree of depression of patients in Wang's study was measured at an unknown time; the severity of depression changes with treatment progress. Lau et al has proved that depression was one of the risk factors for RHD, ${ }^{29}$ but the assessment of RHD in Lau's study was limited to a single-item question; patients might misinterpret the item as asking for their eagerness to go home or disguise their real thoughts in order to escape from the hospital. Therefore, the impact 
of depression on RHD in patients with MDD needs further study.

Patients' perceived readiness of discharge also needs to be researched. In inpatient settings, discharge decisions are typically based on input from the medical staff and/or patients' families. However, a patient's perceived RHD may be different from their care provider's evaluation. ${ }^{16}$ Patients' RHD has previously been proposed as the most influential factor on functional status during the transition from hospital to home. ${ }^{30}$

In summary, to better understand RHD among patients with MDD, this study aims to investigate the current situation of perceived RHD among adult patients with MDD (aim 1), and identify the variables affecting patients' perceptions concerning their RHD (aim 2). At present, assessing patients' perceived RHD is usually not included in routine discharge procedures; our study will provide evidence for health providers (health administrators) to take patients' readiness for discharge into account before discharge, and adjust their discharge planning based on assessment, to make sure discharge is safe both physically and psychologically.

\section{Theoretical Framework}

Meleis' middle range theory of transitions provided a framework of concepts that are relevant to the specific transitional situation of going home from the hospital after hospitalization. ${ }^{31}$ The theory was used to guide identification of variables for this study. Theory of transitions proposes that transition conditions, nature of the transition, and nursing therapeutic practices will affect patterns of response during a transition. In this study, patient characteristics represented the personal and environmental conditions that could facilitate or inhibit the transition process and included the patient's gender, age, marital status, education level, work status, place of residence, whether they live alone or not, per capita monthly household income, and insurance. The nature of the transition was represented by hospitalization factors (length of hospitalization, first hospitalization or not, duration of the disease, comorbidities, types of psychiatric medication, and depression in significant others). Discharge teaching was selected as the nursing therapeutic process to be investigated. Discharge was the pattern of response. The proposed relationships between the study concepts are presented in Figure 1.

\section{Materials and Methods}

\section{Study Design, Setting and Participants}

This is a cross-sectional study design.

The study was conducted in the Mental Health Center of a tertiary general hospital in Hunan Province (China) from March 2019 to September 2019. The Mental Health Center in this tertiary general hospital is not only a national clinical medicine research center, but also a clinical regional center connecting the Eastern and Western regions of China. The center provides mental health services for patients with mental disorders from all over the country and includes 5 inpatient departments and various outpatient services.

The sample size was calculated by the formula $\mathrm{n}=\left(\left(\mathrm{u}_{\alpha / 2}\right.\right.$ $\sigma) / \delta)^{2}, \alpha=0.05, \sigma=1.7, \delta=0.25,{ }^{32}$ hence $n=178$. Taking invalid questionnaires into account, $20 \%$ was added to the calculated sample size. The final sample size was supposed to be larger than 214 .

All the patients with MDD hospitalized at the Mental Health Center at the time of data collection were invited to participate if they fulfilled the following inclusion criteria: (i) were aged 18 years or older; (ii) were diagnosed with MDD according to the Diagnostic and Statistical Manual of Mental Disorders-V (DSM-V); (iii) were discharged within the 24 hours of participation; (iv) were able to understand the questionnaires; (v) volunteered for this survey. The exclusion criteria were those patients who (i) had participated in other discharge intervention studies; (ii) were suffering from severe brain and body illnesses.

During data collection, a total of 230 participants were eligible for this study, but 6 were excluded due to incomplete questionnaires, finally 224 participants completed the valid questionnaires for a $97.4 \%$ response rate.

\section{Instruments}

Data collection was based on four instruments: the general information questionnaire, the readiness for hospital discharge scale (RHDS), the quality of discharge teaching scale (QDTS) and the patient health questionnaire-9 (PHQ-9). A detailed description of each instrument is given below.

The general information questionnaire was designed by this research team based on literature review and expert consultation; it including demographic characteristics (gender, age, marital status, education level, work status, place of residence, living alone or not, per capita monthly household income, and insurance) and disease-related 


\section{Transition Conditions}

Patient Characteristics

-Gender

-Age

-Marital status

-Education level

-Work status

-Place of residence

-Living alone or not

-Per capita monthly household income

-Insurance

Nature of the Transition

Hospitalization Factors

-Length of hospitalization

-First hospitalization or not

-Duration of the disease

-Comorbidities

-Types of psychiatric medication

-Depression in significant others

-The level of patient health questionnaire- 9
Patterns of Response

Discharge

-Readiness for hospital discharge

Figure I The theoretical framework of the study.

characteristics (length of hospitalization, first hospitalization or not, duration of the disease, comorbidities, types of psychiatric medication, depression in significant others).

Patient's perceptions of readiness for discharge was assessed using the RHDS developed by Wiess et al. ${ }^{11}$ It is a 23-item instrument: the first item is a dichotomous question asking patients if they are ready to go home, and it is only used to judge the subjective feelings of patients for discharge and not included in the total score. The other 22 items were scored on an 11-point scale $(0-10,0=$ not at all, ....., 10=totally), which form 4 subscales (personal status, knowledge, coping ability, and expected support). The gross total score ranges from 0 to 220 and the standardized score ranges from 0 to 10 (standardized score=total score/the number of items). The RHD can be divided into four levels based on cut-off points of standardized score $(<7=$ low, $7-7.9=$ moderate, $8-8.9=$ high and 9 $10=$ very high). ${ }^{17}$ The scale has been translated and validated by Zhao in China. ${ }^{33}$ The Chinese version is consistent with the English version in dimension and items with acceptable psychometric characteristics (Cronbach's $\alpha$ coefficient of the scale was 0.92 and the content validity was 0.97 ), but the Chinese author did not provide the cut- off points. Considering the high-maintenance of the scale's structure and features in Chinese version, we would take the original cut-off points in our study.

Educational preparation for discharge was measured using the QDTS developed by Wiess et al. ${ }^{13}$ Discharge teaching was conceptualized as a composite of all teaching received by the patient (from the patient's perspective) during hospitalization, in preparation for being discharged and coping with the post-hospitalization period. The instrument consists of three subscales. The "content" subscale has six paired items representing the amount of "content needed" and "content received" during discharge preparation teaching. The 12-item "delivery" subscale represents the skills of the nurses as educators in providing discharge teaching. The QDTS consists of 24 items and it also used an 11-point Likert scale $(0-10,0=$ not at all, ..., $10=$ very much), where higher scores indicate higher patient perceptions of the quality of discharge teaching. The total score is calculated by adding the content received and the delivery subscale scores. The QDTS can be divided into four levels based on cut-off points of standardized score $(<7=$ low, $7-7.9=$ moderate, $8-8.9=$ high and $9-10=$ very high). ${ }^{17}$ The Chinese version of the QDTS 
was revised by Wang in China, ${ }^{34}$ the reported Cronbach's $\alpha$ coefficient and the content validity of the scale were 0.92 and 0.89 respectively.

The PHQ-9 is a self-report questionnaire that measures a respondent's level of depression, developed by Kroenke et al. $^{35}$ The PHQ-9 consists of nine items, asking how often the patient was bothered by various symptoms in the past two weeks. Each item is scored on a 4-point Likert scale, ranging from 0 (not at all) to 3 (almost every day), resulting in a total score of 0 to 27 . A high score suggests a higher level of depression. The total score can be categorized into five groups: no depression (0-4), mild depression (5-9), moderate depression (10-14), moderately severe depression (15-19), and severe depression (20 27). A Chinese version PHQ-9 is available on the website named Patient Health Questionnaire (PHQ) Screeners. ${ }^{36}$ The validity as well as the reliability of the PHQ-9 have consistently been verified in the Chinese population. The Cronbach's $\alpha$ coefficient of Chinese version scale was 0.86 , the correlation coefficient between total score of PHQ-9 and total score of HAMD (Hamilton depression scale) was $0.811 .^{37}$

\section{Data Collection}

Researchers identified eligible patients by communicating with nurses working in inpatient departments. The nurses asked potential participants about their willingness to participate in the survey. Then, they transferred the potential participants to the researchers. After oral informed consent, participants were required to fill out the questionnaires; the researcher stood nearby and was always ready to give participants consultation. For those patients with dyslexia or visual impairment, face-to-face oral questionnaires were used by researchers. Participants were also informed that they could withdraw from the study at any time. All the questionnaires were collected on the spot. To avoid missing data or obvious logical errors, researchers would check the questionnaires after each questionnaire was finished.

\section{Data Analysis}

Statistical analysis was performed using IBM SPSS 26.0 software. The categorical variables were presented as frequencies of occurrence and percentages. Mean \pm standard deviation was used to describe the patient-reported RHD (aim 1) and QDTS. Univariate analysis was performed to identify demographic or disease-related factors that were significantly associated with RHD. Differences between two groups were analyzed using the Wilcoxon rank sum test and among three or more groups were analyzed using the Kruskal-Wallis test. The relationship between RHDS and QDTS were analyzed using the Spearman test. ${ }^{38,39}$ Patients were categorized into the low patient-RHD group (RHDS $<7$ ), the moderate patientRHD group (RHDS=7-7.9), the high patient-RHD group (RHDS $=8-8.9)$ or the very high patient-RHD group (RHDS=9-10). Ordinal logistic regression was performed to evaluate the factors influencing RHD (aim 2) including all statistically significant variables in univariate factor analysis process $(p<0.05)$, odds ratios (OR), 95\% Confidence Intervals (CI), and their associated $p$ values were reported. All the statistical tests were two-sided and the result with $p<0.05$ was regarded as a statistically significant.

\section{Results}

\section{Patients' Demographic Characteristics}

Responses from 224 individuals (75 men, 149 women); median age $=34$ (interquartile $=23-51$ ) yearsyewere included in the analysis. Most of them were married (56.7\%, $\mathrm{n}=127)$, unemployed $(71.9 \%, \mathrm{n}=161)$, living with others $(94.6 \%, n=212)$. See Table 1 for more details.

\section{Patients' Disease-Related Characteristics}

Most of participants have depression symptoms when they were discharged $(87.5 \%, \mathrm{n}=196)$, a large proportion of patients have suffered from depression for more than 2 years $(52.2 \%, \mathrm{n}=117)$, were admitted for the first time $(62.5 \%, n=140)$, and their length of hospitalization were concentrated on $14-28$ days $(67.0 \%, n=150)$. See more details in Table 2.

\section{RHDS Among Patients with MDD}

For the first dichotomous item (asking patients if they are ready to go home), $86.6 \%(n=194)$ of patients selected "yes" which meant they perceived they were ready for discharge. The mean of gross total score for RHDS among patients with MDD was 162.22 $(S D=30.69)$. And the standardized mean score was $7.37(S D=1.40)$, which was at a moderate level. The highest mean score of four dimensions was coping ability (Mean=8.48, $S D=1.57$ ), followed by expected support $\quad($ Mean $=7.42, \quad S D=2.02)$, personal status (Mean=7.26, $S D=1.60)$, and knowledge (Mean=7.04, 
Table I Patients' Demographic Characteristics

\begin{tabular}{|c|c|c|c|c|c|c|c|}
\hline \multirow[t]{2}{*}{ Characteristics } & \multirow[t]{2}{*}{ n (\%) } & \multicolumn{4}{|c|}{ The Levels of RHDS } & \multirow[t]{2}{*}{ ZIH } & \multirow[t]{2}{*}{$p$} \\
\hline & & Low & Moderate & High & Very High & & \\
\hline $\begin{array}{l}\text { Gender } \\
\text { Male } \\
\text { Female }\end{array}$ & $\begin{array}{l}75(33.5) \\
149(66.5)\end{array}$ & $\begin{array}{l}26(34.7) \\
55(36.9)\end{array}$ & $\begin{array}{l}\text { I8 (24.0) } \\
4 \text { I (27.5) }\end{array}$ & $\begin{array}{l}20(26.7) \\
33(22.1)\end{array}$ & $\begin{array}{l}\text { II (14.6) } \\
20(13.5)\end{array}$ & $-0.605^{\mathrm{a}}$ & 0.545 \\
\hline $\begin{array}{l}\text { Age (years) } \\
\quad<34 \\
\quad \geq 34\end{array}$ & $\begin{array}{l}108(48.2) \\
116(51.8)\end{array}$ & $\begin{array}{l}46(42.6) \\
35(30.2)\end{array}$ & $\begin{array}{l}27(25.0) \\
32(27.6)\end{array}$ & $\begin{array}{l}23(21.3) \\
30(25.9)\end{array}$ & $\begin{array}{l}12(11.1) \\
19(16.4)\end{array}$ & $-1.976^{\mathrm{a}}$ & 0.048 \\
\hline $\begin{array}{l}\text { Marital status } \\
\text { Single } \\
\text { Married } \\
\text { Others }\end{array}$ & $\begin{array}{l}79(35.3) \\
127(56.7) \\
18(8.0)\end{array}$ & $\begin{array}{l}35(44.3) \\
40(31.5) \\
6(33.4)\end{array}$ & $\begin{array}{l}20(25.3) \\
35(27.6) \\
4(22.2)\end{array}$ & $\begin{array}{l}17(21.5) \\
32(25.2) \\
4(22.2)\end{array}$ & $\begin{array}{l}7(8.9) \\
20(15.7) \\
4(22.2)\end{array}$ & $4.436^{\mathrm{b}}$ & 0.109 \\
\hline $\begin{array}{l}\text { Education level } \\
\text { Middle school or below } \\
\text { High school/technical secondary school } \\
\text { Post-secondary school or above }\end{array}$ & $\begin{array}{l}65(29.0) \\
76(33.9) \\
83(37.1)\end{array}$ & $\begin{array}{ll}21 & (32.3) \\
36 & (47.4) \\
24 & (28.9)\end{array}$ & $\begin{array}{l}25(38.5) \\
15(19.7) \\
19(22.9)\end{array}$ & $\begin{array}{l}\text { II (16.9) } \\
18(23.7) \\
24(28.9)\end{array}$ & $\begin{array}{l}8(12.3) \\
7(9.2) \\
16(19.3)\end{array}$ & $6.956^{\mathrm{b}}$ & 0.031 \\
\hline $\begin{array}{l}\text { Work status } \\
\text { Employed } \\
\text { Unemployed }\end{array}$ & $\begin{array}{l}63(28.1) \\
161(71.9)\end{array}$ & $\begin{array}{l}16(25.4) \\
65(40.4)\end{array}$ & $\begin{array}{l}12(19.0) \\
47(29.2)\end{array}$ & $\begin{array}{l}18(28.6) \\
35(21.7)\end{array}$ & $\begin{array}{l}\text { I7 (27.0) } \\
\text { I4 (8.7) }\end{array}$ & $-3.492^{\mathrm{a}}$ & $<0.001$ \\
\hline $\begin{array}{l}\text { Place of residence } \\
\text { Urban } \\
\text { Rural }\end{array}$ & $\begin{array}{l}\mid 76(78.6) \\
48(2 \mid .4)\end{array}$ & $\begin{array}{l}56(31.8) \\
25(52.1)\end{array}$ & $\begin{array}{l}47(26.7) \\
12(25.0)\end{array}$ & $\begin{array}{l}44(25.0) \\
9(18.8)\end{array}$ & $\begin{array}{l}29(16.5) \\
2(4.1)\end{array}$ & $-2.94 I^{\mathrm{a}}$ & 0.003 \\
\hline $\begin{array}{l}\text { Living alone or not } \\
\text { Yes } \\
\text { No }\end{array}$ & $\begin{array}{l}12(5.4) \\
212(94.6)\end{array}$ & $\begin{array}{l}4(33.3) \\
77(36.3)\end{array}$ & $\begin{array}{l}\text { I (8.3) } \\
58(27.4)\end{array}$ & $\begin{array}{l}5(41.7) \\
48(22.6)\end{array}$ & $\begin{array}{l}2(16.7) \\
29(13.7)\end{array}$ & $-0.850^{\mathrm{a}}$ & 0.395 \\
\hline $\begin{array}{l}\text { Per capita monthly household income (RMB) } \\
\quad<2000 \\
2000-3999 \\
4000-5999 \\
\geq 6000\end{array}$ & $\begin{array}{l}27(12.1) \\
88(39.3) \\
75(33.5) \\
34(15.1)\end{array}$ & $\begin{array}{l}13(48.1) \\
27(30.7) \\
28(37.3) \\
13(38.3)\end{array}$ & $\begin{array}{l}9(33.3) \\
24(27.3) \\
20(26.7) \\
6(17.6)\end{array}$ & $\begin{array}{l}5(18.6) \\
21(23.9) \\
18(24.0) \\
9(26.5)\end{array}$ & $\begin{array}{l}0(0.0) \\
16(18.1) \\
9(12.0) \\
6(17.6)\end{array}$ & $6.097^{b}$ & 0.107 \\
\hline
\end{tabular}

Notes: ${ }^{a}$ Wilcoxon rank sum test. ${ }^{\text {b } K r u s k a l-W a l l i s ~ t e s t . ~}$

Abbreviations: RHDS, readiness for hospital discharge scale; RMB, the China Yuan (CNY).

$S D=1.71$ ). Table 3 shows the percentage of different levels based on the cut-off points of RHDS.

\section{QDTS Among Patients with MDD}

The mean of gross total score for QDTS among patients with MDD was $114.57(S D=33.99)$. And the standardized mean score for it was $6.36(S D=1.89)$. The order of the three dimensions from high to low was delivery (Mean=6.71, $S D=2.06$ ), content needed (Mean=6.39, $S D=2.09$ ), and content received (Mean=5.68, $S D=2.05$ ).

\section{The Results of Univariate Analysis}

In Table 1, univariate analysis showed that the patients' RHDS was related to the following demographic characteristics: age $(p=0.048)$, education level $(p=0.031)$, work status $(p<0.001)$, and place of residence $(p=0.003)$.

In Table 2, univariate analysis showed that the patients' RHDS was related to the following diseaserelated characteristics: the level of PHQ-9 $(p<0.001)$, duration of the disease $(p=0.048)$, first hospitalization 
Table 2 Patients' Disease-Related Characteristics

\begin{tabular}{|c|c|c|c|c|c|c|c|}
\hline \multirow[t]{2}{*}{ Characteristics } & \multirow[t]{2}{*}{ n (\%) } & \multicolumn{4}{|c|}{ The Levels of RHDS } & \multirow[t]{2}{*}{$H I Z$} & \multirow[t]{2}{*}{$p$} \\
\hline & & Low & Moderate & High & Very High & & \\
\hline The level of PHQ-9 & & & & & & $53.852^{\mathrm{a}}$ & $<0.001$ \\
\hline No & $28(12.5)$ & $2(7.1)$ & $6(2 I .4)$ & $10(35.7)$ & $10(35.8)$ & & \\
\hline Mild & $62(27.7)$ & II (I7.7) & $14(22.6)$ & $22(35.5)$ & $15(24.2)$ & & \\
\hline Moderate & $56(25.0)$ & $22(39.3)$ & $22(39.3)$ & $10(17.9)$ & $2(3.5)$ & & \\
\hline Moderately severe & $57(25.4)$ & $30(52.6)$ & $16(28.1)$ & $8(14.0)$ & $3(5.3)$ & & \\
\hline Severe & $21(9.4)$ & $16(76.2)$ & I (4.8) & $3(14.3)$ & I (4.7) & & \\
\hline Duration of the disease (mouths) & & & & & & $6.084^{\mathrm{a}}$ & 0.048 \\
\hline$<12$ & $64(28.6)$ & $18(28.1)$ & $16(25.0)$ & $16(25.0)$ & $14(21.9)$ & & \\
\hline $12-23$ & $43(19.2)$ & $20(46.5)$ & $10(23.3)$ & II (25.6) & $2(4.6)$ & & \\
\hline$\geq 24$ & $117(52.2)$ & $43(36.8)$ & $33(28.2)$ & $26(22.2)$ & $15(12.8)$ & & \\
\hline Insurance & & & & & & $-0.018^{\mathrm{b}}$ & 0.986 \\
\hline Yes & $202(90.2)$ & $75(37.1)$ & $51(25.2)$ & $45(22.3)$ & $31(15.4)$ & & \\
\hline No & $22(9.8)$ & $6(27.2)$ & $8(36.4)$ & $8(36.4)$ & $0(0.0)$ & & \\
\hline First hospitalization or not & & & & & & $-3.484^{b}$ & $<0.001$ \\
\hline Yes & $140(62.5)$ & $36(25.7)$ & $46(32.9)$ & $33(23.6)$ & $25(17.8)$ & & \\
\hline No & $84(37.5)$ & $45(53.6)$ & $13(15.5)$ & $20(23.8)$ & $6(7.1)$ & & \\
\hline Length of hospitalization (days) & & & & & & $14.472^{\mathrm{a}}$ & 0.001 \\
\hline$<14$ & $29(12.9)$ & $3(10.3)$ & $7(24.1)$ & $13(44.8)$ & $6(20.8)$ & & \\
\hline | $4 \sim 28$ & $150(67.0)$ & $58(38.7)$ & $37(24.7)$ & $31(20.7)$ & $24(15.9)$ & & \\
\hline$>28$ & $45(20.1)$ & $20(44.4)$ & $15(33.3)$ & $9(20.0)$ & I (2.3) & & \\
\hline Comorbidities & & & & & & $-0.632^{b}$ & 0.528 \\
\hline Yes & $156(69.6)$ & $57(36.5)$ & $39(25.0)$ & $33(21.2)$ & $27(17.3)$ & & \\
\hline No & $68(30.4)$ & $24(35.3)$ & $20(29.4)$ & $20(29.4)$ & $4(5.9)$ & & \\
\hline Types of psychiatric medication & & & & & & $4.741^{\mathrm{a}}$ & 0.192 \\
\hline 1 & $18(8.0)$ & $10(55.6)$ & $4(22.2)$ & $3(16.7)$ & I (5.5) & & \\
\hline 2 & $88(39.3)$ & $25(28.4)$ & $29(33.0)$ & $22(25.0)$ & $12(13.6)$ & & \\
\hline 3 & $83(37.1)$ & $31(37.3)$ & $18(2 \mid .7)$ & $19(22.9)$ & $15(18.1)$ & & \\
\hline$\geq 4$ & $35(15.6)$ & $15(42.9)$ & $8(22.9)$ & $9(25.7)$ & $3(8.5)$ & & \\
\hline Depression in significant others & & & & & & $-0.245^{b}$ & 0.806 \\
\hline Yes & $85(37.9)$ & $33(38.8)$ & $17(20.0)$ & $21(24.7)$ & $14(16.5)$ & & \\
\hline No & $139(62.1)$ & $48(34.5)$ & $42(30.2)$ & $32(23.0)$ & $17(12.3)$ & & \\
\hline
\end{tabular}

Notes: ${ }^{a}$ Kruskal-Wallis test. ${ }^{b}$ Wilcoxon rank sum test.

Abbreviations: RHDS, readiness for hospital discharge scale; PHQ-9, patient health questionnaire-9.

Table 3 The Levels of Readiness for Hospital Discharge Scale of Patients with Major Depressive Disorder

\begin{tabular}{|l|l|l|}
\hline The Levels of RHDS & $\mathbf{n}$ & $\%$ \\
\hline Low & 81 & 36.2 \\
Moderate & 59 & 26.3 \\
High & 53 & 23.7 \\
Very high & 31 & 13.8 \\
\hline
\end{tabular}

Abbreviation: RHDS, Readiness for Hospital Discharge Scale.
Table 4 Results of Spearman Correlation Analysis

\begin{tabular}{|l|l|l|}
\hline Variables & RHDS & $\boldsymbol{p}$ \\
\hline QDTS & 0.449 & $<0.00 \mathrm{I}$ \\
QDTS - Content needed & 0.207 & 0.002 \\
QDTS - Content received & 0.388 & $<0.00 \mathrm{I}$ \\
QDTS - Delivery & 0.430 & $<0.00 \mathrm{I}$ \\
\hline
\end{tabular}

Abbreviations: RHDS, Readiness for Hospital Discharge Scale; QDTS, Quality of discharge teaching scale. 
Table 5 Results of Ordinal Logistic Regression Analysis

\begin{tabular}{|l|l|l|l|l|}
\hline Variables & Standard Error & Odds Ratio & $\mathbf{9 5 \%} \mathbf{C l}$ & $\mathbf{p}$ \\
\hline The level of PHQ-9 & 0.083 & 0.661 & {$[0.562,0.777]$} & $<0.001$ \\
QDTS-Content received & 0.059 & 1.155 & {$[1.029,1.270]$} & 0.003 \\
Education level & 0.107 & 1.244 & {$[1.008,1.536]$} & 0.042 \\
Work status & 0.197 & 1.761 & {$[1.197,2.593]$} & 0.044 \\
Length of hospitalization (days) & 0.144 & 0.527 & {$[0.397,0.699]$} & $<0.001$ \\
\hline
\end{tabular}

Notes: The model goodness-of-fit: Pearson Chi-square: 634.690, $p=0.679$; residual deviance: 489.30I, $p=1.000$.

Abbreviations: Cl, Confidence Intervals; PHQ-9, Patient Health Questionnaire-9; QDTS, Quality of Discharge Teaching Scale.

or not $(p<0.001)$, and length of hospitalization $(p=$ $0.001)$.

In Table 4, Spearman correlational analysis showed that RHDS was positively correlated with QDTS and its three dimensions.

\section{Influencing Factors of RHDS by Ordinal Logistic Regression}

All statistically significant variables in univariate factor analysis process were used as independent variables and the level of RHDS was used as the dependent variable for ordinal logistic regression analysis. Before running the ordinal logistic regression analysis, multicollinearity test between independent variables was done using the Variance Inflation Factor (VIF), and variables were not strongly correlated (the highest value was 2.3 ). The results of the test of parallel lines also suggest that the proportional odds assumption for the regression model was met $\left(x^{2}=31.486, p=0.087\right)$. The goodness-of-fit test suggested that the overall model fit was adequate (Pearson Chisquare: 634.690, $p=0.679$; residual deviance: 489.301, $p=1.000$ ). Moreover, Nilai Mc Fadden $\mathrm{R}^{2}=0.181$, Cox and Snell $\mathrm{R}^{2}=0.383$, Nagelkerke $\mathrm{R}^{2}=0.412$. Results demonstrated that the following factor were influencing factors of RHDS: level of PHQ-9 (OR=0.66), the contentreceived dimension of QDTS $(\mathrm{OR}=1.16)$, education level $(\mathrm{OR}=1.24)$, work status $(\mathrm{OR}=1.76)$ and the length of hospitalization $(\mathrm{OR}=0.53)$. Further information is presented in Table 5 .

\section{Discussion}

Although RHD is an important predictor for patients' rehabilitation, the level of RHD among patients with MDD in our study was at a moderate level $(7.37 \pm 1.40)$, which was lower than those patients with somatic diseases. Weiss investigated the patients from all medical-surgical departments in a tertiary hospital, the reported RHDS was at a high level $(8.0 \pm 0.9) .{ }^{13}$ Reasons may contribute to the difference of study populations. Compared with somatic diseases, patients with MDD may have more worries about dealing with the upcoming problems independently without professional help, such as the adherence of long-time medication, possible relapse, side effects of medicine, impaired social functions, et al. Hence, they may tend to perceive that they are not ready for discharge and have a lower RHDS score. But compared with patients with MDD, the results are inconsistent. The RHDS from Huang's study was lower than ours; ${ }^{27}$ On the contrary, the RHDS from Wang's study was higher than ours. ${ }^{24}$ The differences might be due to small sample sizes, nonrandomized sampling, the homogeneity of the participants, etc., across the three studies, including the present one. More evidence would be needed in the future.

$86.6 \%$ of participants selected "yes" (ready for going home) for the first dichotomous question, which is inconsistent with the percentage $(63.8 \%)$ based on the standard proposed by Bobay (ready for discharge with score of RHDS $\geq 7)$. ${ }^{16}$ The result is in accordance with the results of previous studies. ${ }^{21,24}$ It confirms that patients may overestimate their readiness for discharge or may report false information due to misinterpreting the question or longing for going home.

The score of "knowledge" dimension was the lowest one in the four dimensions of RHDS in our study, which is consistent with the findings of most research about RHD in China, but is inconsistent with studies done in other countries where the dimension with the lowest score varied. ${ }^{19,24,40,41}$ Differences in discharge teaching might be one rationale. Discharge teaching in China is usually delivered by nurses on the day of discharge, it is difficult for nurses to provide individual discharge teaching in such a limited time period, and patients are also eager to go home rather than concentrating on learning. It is recommended that discharge teaching be gradually administered throughout the period of hospitalization rather than being 
completed on the last day. Furthermore, nurses in China have relatively heavy and stressful workloads, which compromises their ability to deliver sufficient discharge teaching. The low score $(6.36 \pm 1.89)$ of discharge teaching in our study demonstrated that discharge teaching provided by medical staff was insufficient. Hence, in the future, we need to enrich the content of health education, improve nurses' discharge teaching skills and efficiency, and pay more attention to patients' individual needs, in order to improve the quality of discharge teaching.

The results of ordinal logistic regression analysis showed that the level of PHQ-9 influenced participants' RHD (OR $=0.66)$, which agrees with Lau's findings. ${ }^{29}$ The main purpose of acute phase treatment is to achieve remission, which is generally defined as a score of HAMD-17 7 , MADRS $\leq 10, \mathrm{BDI} \leq 8$, QIDS-SR $16 \leq 5$ or PHQ- $9 \leq 5$. But due to several possible reasons, such as the requirement of rapid bed turnover rate in general hospitals, family caregivers' strong requests, and so on, the patients might not have achieved remission criteria when they were discharged. In our study, the proportion of participants with a PHQ-9 score of $\leq 5$ was only $17.9 \%$; most patients were not clinically recovered. It is widely known that the more severe the depressive symptoms are, the worse the social function of the patients will be. ${ }^{42}$ It is impossible for patients with impaired social function to perceive high readiness for hospital discharge. This result implicated that medical staff should balance the requirement of bed turnover rate and patients' condition in general hospital to make a discharge decision.

The content-received dimension of QDTS was included in the ordinal logistic regression analysis $(\mathrm{OR}=1.16)$. This outcome is different from that of Wang et al, who found that the content- received and delivery dimensions of QDTS were both influencing factors of RHD of patients with depression. ${ }^{24}$ Several possible reasons are as follows. The first one is the difference in age between both populations. Wang's study involved patient with different age groups, including adolescents, adults and old patients. In our study, most of the patients were adults, only 14 older than 65 years old. Adolescent patients and older patients might have poorer learning and understanding capacities than adults, so they are more demanding than adults in terms of the discharge teaching skills of nurses who work with them. Furthermore, $37.1 \%$ of the patients in our study had a postsecondary education or higher, while the proportion in Wang's study was only $18.0 \%$. Previous research indicated that lower levels of education reduced patients' chances of benefitting from discharge guidance/teaching. ${ }^{29}$ For the patients with higher levels of education, they may care more about content rather than teaching skills. This finding also has important implications for the development of discharge teaching and patients' education.

Discharge teaching should consider patients' backgrounds.

Results also showed that participants' education level was another protective factor of RHDS (OR=1.24). Study conducted by $\mathrm{Bi} \mathrm{L}$ found that participants with higher education level had higher RHDS scores. ${ }^{23}$ Compared with patients with lower education level, they have higher self-efficacy ability, so as to have a higher perception of discharge preparation. ${ }^{43}$ The result suggests that medical staff should try their best to improve patients' self-efficacy and self-care ability during hospitalization, especially for those with lower education level.

Employment was demonstrated to be a protective factor of $\mathrm{RHD}(\mathrm{OR}=1.76)$, this is consistent with Wang's research. ${ }^{34}$ Patients with job might have more complete social support system. In previous studies, it was also confirmed that patients with higher social support had better discharge readiness. ${ }^{44}$ In addition, patients with employment maintain better social functions, it is easier for them to understand and follow medical directions, which might be a facilitator for their discharge. This outcome suggests that nurses should pay more attention to patients who are unemployed, and help them to build their social support system, and promote their social functions.

Length of hospitalization was a risk factor of RHD $(\mathrm{OR}=0.53)$, which is consistent with previous studies. $^{22,40}$ Patients staying long in psychiatric ward are used to depending on the medical staff to arrange their daily life, what they need to do is to follow the medical staff's orders, they feel less stress. When being discharged, they may feel anxious about the upcoming life without professional help, and the continuous care in China is not as good as expected, especially for patients with mental health disorders, patients might be afraid of being discharged. Furthermore, staying long in psychiatric ward limits their social life, lower their social support, even isolates them from society, ${ }^{45}$ which compromise their coping skills. When being discharged, they also worry about if they can cope with the possible stressful situations such as stigma, unemployment, family integrity, and so on, which might 
strengthen their unwillingness to leave hospitals. This result implicates that medical staff should facilitate patients' self-decision making ability, rich their hospital life and improve their coping skills to decrease their dependence on medical staff.

\section{The Limitations of the Study}

Admittedly, there are several limitations of this study. Firstly, the study could not avoid selection bias, which compromised the generalization of the results. All the participants of this study only came from one hospital in Hunan province, although the study hospital is a big mental health center with patients from all over the country. A study on multiple medical centers is suggested in the future. Furthermore, due to time limitations, the researchers did not get follow-up information about the patients' performance after discharge, in metrics such as readmission rate, drug adherence, social function, etc. More studies are needed to explore the effect of RHD on the short-term and long-term outcomes of patients with MDD.

\section{Conclusion and Implication}

In conclusion, the RHD among participants was at a moderate level and more than a third of people with MDD were not ready for readiness. It is strongly suggested for medical staff to take the assessment of RHD as a routine process with proper instrument and to be cautious to patients' overestimation of their RHD. Patients' RHD was influenced by the level of PHQ-9, the content-received dimension of QDTS, education level, work status and the length of hospitalization. The relationship between RHD and the level of PHQ-9 implicates that the requirement to balance the bed turnover rates and patients' condition in general hospitals. To improve RHD, discharge teaching should be tailored according to the patient's background.

\section{Ethics Statements}

This is a minimal risk study, and we applied for an exemption from written informed consent, which was later approved by the Institutional Review Board of Xiangya School of Nursing at Central South University in accordance with the Declaration of Helsinki. Before data collection, we provided patients with an information sheet. After reading it, patients orally expressed their willingness to participate or not. For those who agreed, we gave a questionnaire and thanked those who disagreed. For those who agreed, we gave a questionnaire to them, for those who disagreed, we thanked them for their time. Participants were also informed that they could withdraw from the study at any time. Anonymity and confidentiality were maintained throughout the study. All practices involved in the study were approved by the Institutional Review Board (Letter Number: 2019032).

\section{Acknowledgments}

We are appreciative of all patients in the study. The authors also thank the whole staff of the psychiatric department of the tertiary hospital.

\section{Funding}

This research was funded by the Projects of Postgraduate Independent Exploration and Innovation of Central South University (2020zzts846).

\section{Disclosure}

The authors declare that they have no conflicts of interest in this work.

\section{References}

1. World Health Organization. Depression and Other Common Mental Disorders: Global Health Estimates. Geneva: World Health Organization; 2017. Licence: CC BY-NC-SA 3.0 IGO.

2. Xiang Y, Zhang Q, Wang G, Zeng L, Ungvari GS. Prevalence of mental disorders in China. Lancet Psychiatry. 2019;6(6):467-468. doi:10.1016/S2215-0366(19)30128-2

3. Citrome L, Jain R, Tung A, Landsman-Blumberg PB, Kramer K, Ali S. Prevalence, treatment patterns, and stay characteristics associated with hospitalizations for major depressive disorder. $J$ Affect Disord. 2019;249:378-384. doi:10.1016/j. jad.2019.01.044

4. Xiao S, Tourangeau A, Widger K, Berta W. Discharge planning in mental healthcare settings: a review and concept analysis. Int J Ment Health Nurs. 2019;28(4):816-832. doi:10.1111/inm.12599

5. Maramba PJ, Richards S, Myers AL, Larrabee JH. Discharge planning process - applying a model for evidence-based practice. $J$ Nurs Care Qual. 2004;19(2):123-129. doi:10.1097/00001786-20040400000009

6. Desplenter FA, Laekeman GJ, Simoens SR. Following up patients with depression after hospital discharge: a mixed methods approach. Int J Ment Health Syst. 2011;5(1):28. doi:10.1186/ 1752-4458-5-28

7. Wang H. The Study on the Recovery of Psychosocial Function in Patients in Remission with First-Episode and Recurrent Depression [dissertation]. China: Nanjing Medical University; 2019.

8. Forster AJ, Murff HJ, Peterson JF, Gandhi TK, Bates DW. The incidence and severity of adverse events affecting patients after discharge from the hospital. Ann Intern Med. 2003;138(3):161-167. doi:10.7326/0003-4819-138-3-200302040-00007

9. Liu Y, Yang M, Ding H, et al. A meta-analysis of discharge planning for the rehabilitation effectiveness in patients with mental illness. Chin Ment Health J. 2019;33:893-899. Chinese.

10. American Hospital Association. Guidelines for Discharge Planning. Chicago: AHA; 1984. 
11. Weiss ME, Piacentine LB. Psychometric properties of the Readiness for Hospital Discharge Scale. J Nurs Meas. 2006;14(3):163-180. doi:10.1891/jnm-v14i3a002

12. Weiss ME, Lokken L. Predictors and outcomes of postpartum mothers' perceptions of readiness for discharge after birth. J Obstet Gynecol Neonatal Nurs. 2009;38(4):406-417. doi:10.1111/j.15526909.2009.01040.x

13. Weiss ME, Piacentine LB, Lokken L, et al. Perceived readiness for hospital discharge in adult medical-surgical patients. Clin Nurse Spec. 2007;21(1):31-42. doi:10.1097/00002800-200701000-00008

14. Meng N, Liu R, Wong M, Liao J, Feng C, Li X. The association between patient-reported readiness for hospital discharge and outcomes in patients diagnosed with anxiety disorders: a prospective and observational study. J Psychiatr Ment Health. 2020;27(4):380-392.

15. Mabire C, Bachnick S, Ausserhofer D, Simon M, Match S. Patient readiness for hospital discharge and its relationship to discharge preparation and structural factors: a cross sectional study. Int J Nurs Stud. 2019;90:13-20. doi:10.1016/j.ijnurstu.2018.09.016

16. Bobay KL, Jerofke TA, Weiss ME, Yakusheva O. Age-related differences in perception of quality of discharge teaching and readiness for hospital discharge. Geriatr Nurs. 2010;31(3):178-187. doi:10.1016/j. gerinurse.2010.03.005

17. Weiss ME, Costa LL, Yakusheva O, Bobay KL. Validation of patient and nurse short forms of the Readiness for Hospital Discharge Scale and their relationship to return to the hospital. Health Serv Res. 2014;49(1):304-317. doi:10.1111/1475-6773.12092

18. Xiao Z, Li X, Qiao S, Zhou Y, Shen Z. Coping, social support, stigma, and gender difference among people living with HIV in Guangxi, China. Psychol Health Med. 2018;23(1):18-29. doi:10.1080/13548506.2017.1300671

19. Siow E, Lo SM, Yeung KL, Yeung RSD, Choi KC, Chair SY. Factors and post-discharge outcomes associated with patients' readiness for discharge from the emergency medicine ward: a prospective study. Int Emerg Nurs. 2019;46:100773. doi:10.1016/j.ienj.2019.04.002

20. Weiss ME, Sawin KJ, Gralton K, et al. Discharge teaching, readiness for discharge, and post-discharge outcomes in parents of hospitalized children. $J$ Pediatr Nurs. 2017;34:58-64. doi:10.1016/j. pedn.2016.12.021

21. Liu K, Jiang X. Research on the current status of the level of readiness for hospital discharge of patients underwent kidney transplantation. Nurs J Chin PLA. 2017;34(13):21-25. Chinese.

22. Li X, Zhang Q. Analysis of the status Quo and influencing factors of hospital discharge readiness in patients with endoscopic submucosal dissection. Sichuan Med J. 2017;38(2):215-218. Chinese.

23. Bi L, Wang L, Ma L. Readiness for hospital discharge and its influencing factors in patients after total hip arthroplasty. Chin J Mod Nurs. 2019;25(29):3792-3798. Chinese.

24. Wang M, Wang Y, Meng N, Li X. The factors of patient-reported readiness for hospital discharge in patients with depression: a cross-sectional study. J Psychiatr Ment Health. 2021;28(3):409-421.

25. Turrell SL, Davis R, Graham H, Weiss I. Adolescents with anorexia nervosa: multiple perspectives of discharge readiness. $J$ Child Adolesc Psychiatr Nurs. 2005;18(3):116-126. doi:10.1111/j.17446171.2005.00021.x

26. Ruetsch C, Rupnow MF, Revicki DA, Kosik-Gonzalez C, Greenspan A, Gharabawi G. Pmh46 reliability and validity of the readiness for discharge questionnaire in schizophrenia. Value Health. 2005;8(3):398-399. doi:10.1016/S1098-3015(10)63081-1

27. Huang J, Chu L, Chu L, Bao J, Wu S. Status quo and influencing factors of discharge readiness of patients with depression. J Qilu Nurs. 2020;26(15):69-72. Chinese.
28. Douglas KM, Porter RJ. Longitudinal assessment of neuropsychological function in major depression. Aust N Z J Psychiatry. 2009;43 (12):1105-1117. doi:10.3109/00048670903279887

29. Lau D, Padwal RS, Majumdar SR, et al. Patient-reported discharge readiness and 30-day risk of readmission or death: a Prospective Cohort Study. Am J Med. 2016;129(1):89-95. doi:10.1016/j. amjmed.2015.08.018

30. Howard-Anderson J, Lonowski S, Vangala S, Tseng CH, Busuttil A, Afsar-Manesh N. Readmissions in the era of patient engagement. JAMA Intern Med. 2014;174(11):1870-1872. doi:10.1001/ jamainternmed.2014.4782

31. Meleis AI, Sawyer LM, Im EO, Hilfinger Messias DK, Schumacher K. Experiencing transitions: an emerging middle-range theory. Adv Nurs Sci. 2000;23(1):12-28. doi:10.1097/00012272200009000-00006

32. Zhao H, Feng X, Yu R, Ji X. Nursing of readiness for hospital discharge: a systematic review of the literature. Chin Nurs Manage. 2013;13(6):81-83. Chinese.

33. Zhao H, Feng X, Yu R, Gu D, Ji X. Validation of the Chinese Version of the readiness for hospital discharge scale on patients who have undergone laryngectomy. $J$ Nurs Res. 2016;24(4):321-328. doi:10.1097/JNR.0000000000000126

34. Wang B, Wang H, Yang C. Reliability and validity of the Chinese version of the Quality of Discharge Teaching Scale. Chin J Nurs. 2016;51(6):752-755. Chinese.

35. Kroenke K, Spitzer RL, Williams JB. The PHQ-9: validity of a brief depression severity measure. J Gen Intern Med. 2001;16(9):606-613. doi:10.1046/j.1525-1497.2001.016009606.x

36. Patient Health Questionnaire (PHQ) Screeners [homepage on the Internet]. Amercian: Pfizer; 2002. Available from: https://www. phqscreeners.com/select-screener. Accessed June 20, 2021.

37. Bian CD, He XY, Qian J, Wu WY, Li CB. The reliability and validity of a modified patient health questionnaire for screening depressive syndrome in general hospital outpatients. J Tong Ji Univ. 2009;30 (05):136-140. Chinese.

38. Hauke J, Kossowski T. Comparison of values of Pearson's and Spearman's Correlation Coefficients on the same sets of data. Quageo. 2011;30(2):87-93. doi:10.2478/v10117-011-0021-1

39. Zar JH. Significance testing of the Spearman Rank Correlation Coefficient. J Am Stat Assoc. 1972;67(339):578-580. doi:10.1080/ 01621459.1972 .10481251

40. Nurhayati N, Songwathana P, Vachprasit R. Surgical patients' experiences of readiness for hospital discharge and perceived quality of discharge teaching in acute care hospitals. J Clin Nurs. 2019;28(910):1728-1736. doi:10.1111/jocn. 14764

41. Qiu C, Feng X, Zeng J, Luo H, Lai Z. Discharge teaching, readiness for discharge, and post-discharge outcomes in cataract patients treated with day surgery: a cross-sectional study. Indian J Ophthalmol. 2019;67(5):612-617. doi:10.4103/ijo.IJO_1116_18

42. Diao K. Comparative Study on Psychosocial Function of Patients with Clinically Cured Depression [dissertation]. China: Nanjing Normal University; 2017.

43. Zhang H, Yan L, Wang SY, et al. Investigation and analysis of self-efficacy level and its influencing factors in patients with depression. Chin J New Clin Med. 2015;8(06):565-568. Chinese.

44. Hu ZQ, Ma XL. Correlation among readiness for hospital discharge, quality of discharge education and social support in patients with permanent colostomy. Nurs J Chin PLA. 2019;36(5):33-37. Chinese.

45. Gan MY, Wang Y, Liu YJ, et al. State of illness and social support in long-term in-patients with schizophrenia. China J Health Psychol. 2017;25(6):801-805. Chinese. 


\section{Publish your work in this journal}

Patient Preference and Adherence is an international, peer-reviewed, open access journal that focusing on the growing importance of patient preference and adherence throughout the therapeutic continuum. Patient satisfaction, acceptability, quality of life, compliance, persistence and their role in developing new therapeutic modalities and compounds to optimize clinical outcomes for existing disease states are major areas of interest for the journal. This journal has been accepted for indexing on PubMed Central. The manuscript management system is completely online and includes a very quick and fair peer-review system, which is all easy to use. Visit http:// www.dovepress.com/testimonials.php to read real quotes from published authors. 